\title{
A NOVEL CHAOS BASED MODULATION SCHEME (CS-QCSK) WITH IMPROVED BER PERFORMANCE
}

\author{
K.Thilagam ${ }^{1}$ and K.Jayanthi ${ }^{2}$ \\ ${ }^{1}$ Research Scholar, Department of ECE, \\ Pondicherry Engg. College, Puducherry, India \\ thilagam.k@pec.edu \\ ${ }^{2}$ Associate Professor, Department of ECE, \\ Pondicherry Engg. College, Puducherry, India \\ jayanthi@pec.edu
}

\begin{abstract}
In recent years, various chaos based modulation schemes were evolved, of which the CS-DCSK modulation technique provides better BER performance and bandwidth efficiency, due to its code domain approach. The QCSK modulation technique provides double benefit: higher data rate with similar BER performance and same bandwidth occupation as DCSK. By combining the advantage of code shifted differential chaos shift keying (CS-DCSK) and Quadrature chaos shift keying (QCSK) scheme, a novel CS-QCSK modulation scheme called code shifted Quadrature chaos shift keying is proposed. The noise performance of CS-QCSK is better to most conventional modulation schemes and also provides an increased data transmission rates with greatly improved robustness. Analytical expressions for the bit-error rates are derived for both AWGN channel and Rayleigh multipath fading channel. The simulation result shows that the proposed method outperforms classical chaotic modulation schemes in terms of bit error rate $(B E R)$.
\end{abstract}

\section{KEYWORDS}

Differential chaos shift keying (DCSK) ; Quadrature chaos shift keying (QCSK); Code shifted differential chaos shift keying (CS-DCSK); code shifted Quadrature chaos shift keying (CSQCSK); Bit Error Rate(BER).

\section{INTRODUCTION}

In the last few years, a great research effort has been devoted, concerning chaotic carrier modulation. In contrary to the conventional modulation schemes, a wideband, non-periodic chaotic signal is used as carrier, which results in good correlation characteristics and robustness against multipath fading effects. The basic concept of chaos based modulation techniques for coherent and non-coherent systems have been analyzed and studied in [1] \&[2]. For a coherent system, the receiver needs an exact replica of the chaotic signal, such robust synchronization techniques are still not realizable in a practical environment [3].It is worth mentioning the evolution of various types chaos based modulation schemes and their significance and this section is devoted for summarizing the literature survey/ research findings of such schemes. The DCSK scheme, discussed in [4] represents a more robust non-coherent scheme, in which the exact knowledge of the chaotic basis functions is not needed at the receiver. To further enhance the DCSK scheme, frequency-modulated DCSK (FM-DCSK) was introduced to overcome the 
varying bit-energy problem in DCSK, which is very well explored in [5], [6]. The study of multipath performance of the frequency-modulated DCSK (FM-DCSK) system is analyzed in [8],[12]. The analysis was simulation based and the path that suffers from random fading, to be incorporated in the channel model was assumed an ideal constant gain value.

In [7], the role of synchronization in digital communications using chaos was discussed. At receiver, the two pieces of chaotic signals are correlated, then the binary symbol is decoded based on the sign of the correlator output. The DCSK communication scheme, which exploit the repetitive nature of the chaotic signal, extending from simple binary communications to more sophisticated detectors, have been discussed [8]. Multipath performance of binary DCSK systems using a standard correlation detector was discussed in [9]-[10]. Quadrature CSK (QCSK) is a multilevel version of DCSK, based on the generation of an orthogonal of chaotic functions. It allows an increase in data rate occupying same bandwidth with respect to DCSK [11]. In [13],[18] the performance of the DCSK system over a channel with Rayleigh fading or Ricean fading was discussed with the necessity to model the effects of multipath delay spread as well as fading. A multiple-access technique with differential chaos shift keying using a one dimensional iterative map to generate the chaotic signals for all users and similar average data rates for the users have been discussed [14]-[15],[19]. In [16] FM-QCSK discusses the generation of inherent wideband signal with constant energy per bit, which can be achieved by using the combination of frequency modulation with QCSK. The high-level constellation in FM-QACSK which can improve the speed of chaos shift keying is examined in [17] .The ultra wide band systems based on DCSK and FM-DCSK schemes and the implementation in both analogy and digital technology is discussed in [20].The DCSK system incorporated with two-user cooperative diversity technique and multiple accessing is adopted and discussed in[21] as a result excellent crosscorrelation characteristics of Walsh code sequences is obtained. CS-DCSK uses code domain approach, the reference and the information bearing signals are transmitted at the same time slots, it offers better BER performance and bandwidth efficiency, as discussed in [22]. In this paper, a novel CS-QCSK modulation scheme is proposed, which is the combination of CS-DCSK and QCSK modulation schemes. In addition to high data rates, it offers the advantage of both the CSDCSK and QCSK schemes [22], [11].

The remaining part of the paper is organized as follows: In section 2, the proposed system model and problem formulation is described. Section 3, elaborates the analytical BER derivation for different channel conditions. Simulation results are discussed in Section 4. Section 5, deals with the conclusion of the paper.

\section{OVERVIEW ON CHAOS BASED MOdulation SCHEMES}

In order to explain the CS-QCSK system, a brief introduction to DCSK, QCSK and CS-DCSK methods is essential and details are given in this section.

\subsection{Differential Chaos Shift Keying (DCSK)}

In DCSK system, for each symbol period two chaotic sample functions are used to represent, one bit of information. The transmitted DCSK signal has two parts, the first part of the signal is reference signals, while the second denotes the information-bearing signals. If the bit ' 1 ' is to transmitted, then the information bearing signal is the replica of the reference part. If the bit ' 0 ' is to be transmitted, then the information bearing signal is the inverted copy of the reference part. The i-th symbol can be represented as,

$$
\mathrm{S}_{\text {DCSK }}(\mathrm{t})=\left\{\begin{array}{cl}
\mathrm{x}(\mathrm{t}) & \mathrm{t}_{\mathrm{i}} \leq \mathrm{t}<\left(t_{i}+\frac{T}{2}\right) \\
\mp \mathrm{x}(\mathrm{t}-\mathrm{T} / 2) & \left(t_{i}+\frac{T}{2}\right) \leq t<\left(t_{i}+T\right)
\end{array}\right.
$$


where, ' $\mathrm{T}$ ' is the symbol duration. In the receiver, the original information is extracted by computing the correlation between two received sample functions. The output of the correlator is sampled over each symbol period and the output is finally given to the decision device to determine the binary values 1 's or 0 's.

\subsection{Quadrature Chaos Shift Keying (QCSK)}

Similar to DCSK method, each symbol period of QCSK also has two parts, but the modification is, information-bearing signals holds two bits of information by means of quadrature chaos shift keying technique. Since two bits of information are transmitted, it is possible for QCSK scheme to obtain higher data rate. Quadrature chaotic signals are produced by an orthonormal basis chaotic sample functions $x(t)$ and $y(t)$. Let, $x(t)$ be the chaotic reference signal, assuming that the signal $\mathrm{x}$ has zero mean value and is defined as

$$
x(t)=\sum_{k=1}^{\infty} f_{k} \sin \left(k \omega t+\varphi_{k}\right)
$$

and $y(t)$ be the quadrature chaotic reference signal, obtained by changing the phase of each fourier frequency component by $\pi / 2$, and is defined as,

$$
y(t)=\sum_{k=1}^{\infty} f_{k} \sin \left(k \omega t+\varphi_{k}-\pi / 2\right)
$$

The signals $x(t)$ and $y(t)$ are orthogonal in the interval $I_{t}=[0, t]$ and is defined as,

$$
x \perp y \Leftrightarrow \int_{0}^{\tau} x(t) y(t) d t=0
$$

The transmitted QCSK signal is given by,

$$
\mathrm{S}_{\mathrm{QCSK}}(\mathrm{t})= \begin{cases}\sqrt{E_{b}} \mathrm{c}_{\mathrm{x}}(\mathrm{t}) & 0<\mathrm{t}<\frac{T}{2} \\ \sqrt{E_{b}}\left(\mathrm{a}_{1} \mathrm{c}_{\mathrm{x}}(\mathrm{t}-\mathrm{T} / 2)+\mathrm{a}_{2} \mathrm{c}_{\mathrm{y}}(\mathrm{t}-\mathrm{T} / 2)\right) & \frac{T}{2} \leq t<T\end{cases}
$$

where $E_{b}$ is the bit energy over $T / 2$ period, satisfying the orthogonal relations.

$\mathrm{C}_{\mathrm{x}}(\mathrm{t}-\mathrm{T} / 2)$ is chaotic signal with duration $\mathrm{T} / 2$ and $\mathrm{C}_{\mathrm{y}}(\mathrm{t}-\mathrm{T} / 2)$ is chaotic signal orthogonal to

$\mathrm{C}_{\mathrm{x}}(\mathrm{t}-\mathrm{T} / 2)$ with duration $\mathrm{T} / 2$.

\subsection{Code Shifted - Differential Chaos Shift Keying (CS-DCSK)}

In DCSK, the reference and the information bearing signals are transmitted in two consecutive time slots because of its TDMA approach. This time domain approach provides two independent channels for the transmission of reference and information bearing signals. With this, it requires a delay component both in the modulator and demodulator circuits and halves the data rate. To overcome this drawback, an alternative approach used is CS-DCSK, where both the reference and the information bearing signals are transmitted in the same time slot because of its code domain approach (i.e) the two signals are separated by walsh codes instead of time delay. The transmitted CS-DCSK signal is given by,

$$
\mathrm{S}_{\mathrm{b}}(\mathrm{t})=\sum_{k=0}^{N-1} \mathrm{~W}_{\mathrm{R}, \mathrm{k}+1} \mathrm{C}\left(\mathrm{t}-\mathrm{kT}_{\mathrm{c}}\right)+\mathrm{a} \sum_{\mathrm{k}=0}^{\mathrm{N}-1} \mathrm{~W}_{\mathrm{I}, \mathrm{k}+1} \mathrm{C}\left(\mathrm{t}-\mathrm{kT}_{\mathrm{c}}\right) \quad \mathrm{T}_{\mathrm{S}}=\mathrm{NT}_{\mathrm{C}}
$$


Where, $\mathrm{W}_{\mathrm{R}, \mathrm{k}+1}$ is the reference signal, $\mathrm{W}_{\mathrm{I}, \mathrm{k}+1}$ is the information signal, $\mathrm{C}\left(\mathrm{t}-\mathrm{kT}_{\mathrm{c}}\right)$ is the chaotic signal, $T_{s}$ is the symbol duration and $T_{c}$ is the chip duration. The limitation of this system is, with the increased complexity the Bit Error Rate obtained by this system is more or less similar when compared with the existing system.

\subsection{System Model of CS-QCSK Modulation}

The aim of this section is to illustrate the practical importance of CS-QCSK modulation scheme, whose simplified transmitter and receiver block diagram are shown in figure.1and figure. 2 respectively. A baseband system is considered for simplicity. But it is understood, that if the scheme is to be employed for wireless communications a modulator is in need to generate the corresponding RF passband signal. Furthermore, it is assumed that the description of the CSQCSK scheme in the continuous-time domain admits an equivalent discrete-time representation. It discussed in the above, briefly about the advantage of CS-DCSK and QCSK schemes, by combining these two techniques a novel CS-QCSK modulation scheme can be arrived at.

\subsubsection{Transmitter}

In CS-QCSK, the symbol $\mathrm{S}$ is transmitted with the reference signal and information signal in the same time slot but separated by Walsh code sequences. The CS-QCSK transmitted signal is given by,

$$
\mathrm{S}_{\mathrm{b}}(\mathrm{t})=\sum_{k=0}^{N-1} \mathrm{~W}_{\mathrm{R}, \mathrm{k}+1} \mathrm{C}_{\mathrm{x}}\left(\mathrm{t}-\mathrm{kT} \mathrm{T}_{\mathrm{c}}\right)+\mathrm{a}_{1} \sum_{k=0}^{\mathrm{N}-1} \mathrm{~W}_{\mathrm{II}, \mathrm{k}+1} \mathrm{C}_{\mathrm{x}}\left(\mathrm{t}-\mathrm{kT}_{\mathrm{c}}\right)+\mathrm{a}_{2} \sum_{k=0}^{\mathrm{N}-1} \mathrm{~W}_{\mathrm{I} 2, \mathrm{k}+1} \mathrm{C}_{\mathrm{y}}\left(\mathrm{t}-\mathrm{kT}_{\mathrm{c}}\right) \quad \mathrm{T}_{\mathrm{S}}=\mathrm{NT}_{\mathrm{C}}
$$

Where $a_{1} C\{-1,1\}, a_{2} C\{-1,1\}$ is mapped from $b \in\{0,1\}$ which is the information bit to be transmitted. This scheme uses different Walsh code for the reference and information signal , where $\mathrm{W}_{\mathrm{R}, \mathrm{k}+1}$ represent the Walsh code for reference signal and $\mathrm{W}_{\mathrm{I} 1, \mathrm{k}+1}, \mathrm{~W}_{\mathrm{I} 2, \mathrm{k}+1}$ represent the Walsh code for information signal, $\mathrm{C}(\mathrm{t})$ is the chaotic signal with duration

of $\mathrm{T}_{\mathrm{c}}$. Both the reference and the information signal are transmitted in the same time slot as given in equation (7). The orthogonality of two signals are given by,

$$
\begin{aligned}
\mathrm{C}_{\mathrm{x}}\left(\mathrm{t}-\mathrm{kT}_{\mathrm{c}}\right) & =\left\{\begin{array}{cc}
\mathrm{c}_{\mathrm{x}}(\mathrm{t}) & \mathrm{kT}_{\mathrm{c}} \leq \mathrm{t}<(k+1) \mathrm{T}_{\mathrm{c}} \\
0 & \text { otherwise }
\end{array}\right. \\
\mathrm{C}_{\mathrm{y}}\left(\mathrm{t}-\mathrm{kT}_{\mathrm{c}}\right) & =\left\{\begin{array}{cc}
\mathrm{c}_{\mathrm{y}}(\mathrm{t}) & \mathrm{kT}_{\mathrm{c}} \leq \mathrm{t}<(k+1) \mathrm{T}_{\mathrm{c}} \\
0 & \text { otherwise }
\end{array}\right.
\end{aligned}
$$

Let,

$$
\begin{aligned}
& \Delta=\int_{0}^{T_{s=N T_{c}}} \sum_{k=0}^{N-1} \mathrm{~W}_{\mathrm{R}, \mathrm{k}+1} \mathrm{C}_{\mathrm{x}}\left(\mathrm{t}-\mathrm{kT}_{\mathrm{c}}\right) \mathrm{a}_{1} \sum_{k=0}^{\mathrm{N}-1} \mathrm{~W}_{\mathrm{I} 1, \mathrm{k}+1} \mathrm{C}_{\mathrm{x}}\left(\mathrm{t}-\mathrm{kT}_{\mathrm{c}}\right) \mathrm{a}_{2} \sum_{k=0}^{\mathrm{N}-1} \mathrm{~W}_{\mathrm{I} 2, \mathrm{k}+1} \mathrm{C}_{\mathrm{y}}\left(\mathrm{t}-\mathrm{kT}_{\mathrm{c}}\right) \cdot d t \\
& E_{b}=\int_{0}^{T_{s}} c^{2}(t) c_{y}(t) \cdot d t \\
& (.)^{T}=\text { Transporse of vector. }
\end{aligned}
$$




$$
\begin{aligned}
& \mathrm{c}_{\mathrm{x}}(\mathrm{t})=\mathrm{C}_{\mathrm{x}}\left(\mathrm{t}-\mathrm{kT}_{\mathrm{c}}\right) ; \quad \forall k \\
& \mathrm{c}_{y}(\mathrm{t})=\mathrm{C}_{y}\left(\mathrm{t}-\mathrm{kT}_{\mathrm{c}}\right) ; \quad \forall k
\end{aligned}
$$

The orthogonality of the signal is assured by walsh code sequences, therefore the reference and the information signal are independent of the chaotic carrier.

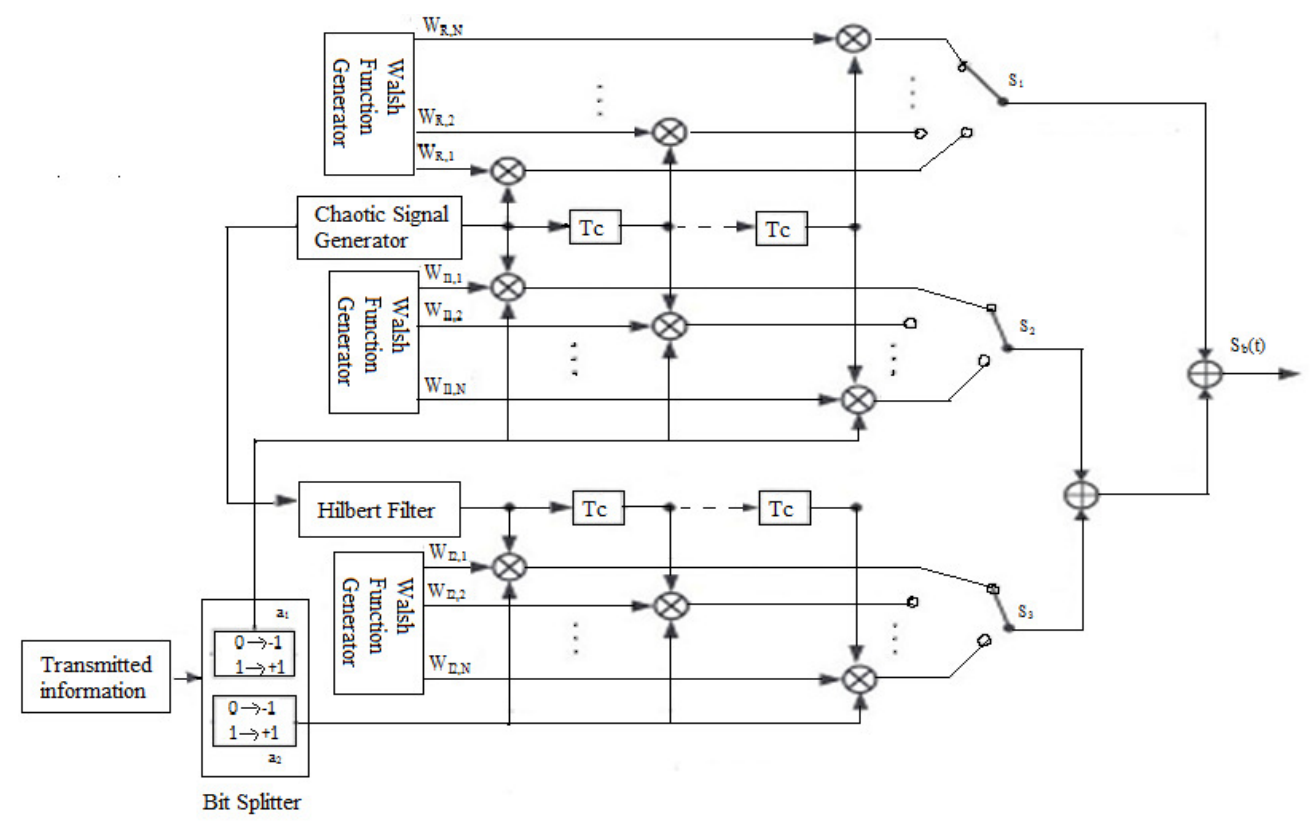

Figure.1 Block diagram of CS-QCSK Transmitter

Referring to the above transmitter block diagram, the CS-QCSK modulation scheme consist of chaos signalgenerator,which generates chaos signal $C_{x}(t)$ and its orthogonal signal $C_{y}(t)$. The orthogonal signal is obtained by taking the Hilbert transform of the chaos signal $C_{x}(t)$. The transmitter block consists of three Walsh function generator, which generates three different Walsh code sequences that are orthogonal in nature. It has $(\mathrm{N}-1)$ delay elements of $\mathrm{T}_{c}$ chip duration. The three Walsh function generator, generate Walsh codes, $W_{R, k+1}$ for reference signal, and $\mathrm{W}_{\mathrm{Il}, \mathrm{k}+1}, \mathrm{~W}_{\mathrm{I} 2, \mathrm{k}+1}$ for information signal. The reference signal of Walsh code $\mathrm{W}_{\mathrm{R}, \mathrm{k}+1}$ is multiplied with the chaos signal and the corresponding output is obtained by the switching unit S1.It has a bit splitter, which splits the input bit stream into odd and even sequences. The information signal of Walsh code WI1, $\mathrm{k}_{+1}$ is multiplied with the odd sequence of bits and the chaos signal, the corresponding output is obtained by the switching unit $\mathrm{S}_{2}$. The information signal of Walsh code $\mathrm{W}_{\mathrm{I} 2, \mathrm{k}+1}$ is multiplied with the even sequence of bits and the orthogonal chaos signal, the corresponding output is obtained by the switching unit $S_{3}$.The output obtained at the switching unit $S_{2}$ and $S_{3}$ are summed and it is further summed with the switching unit $S 1$ to obtain the final output. The CS-QCSK signal is finally obtained. 


\subsubsection{Receiver}

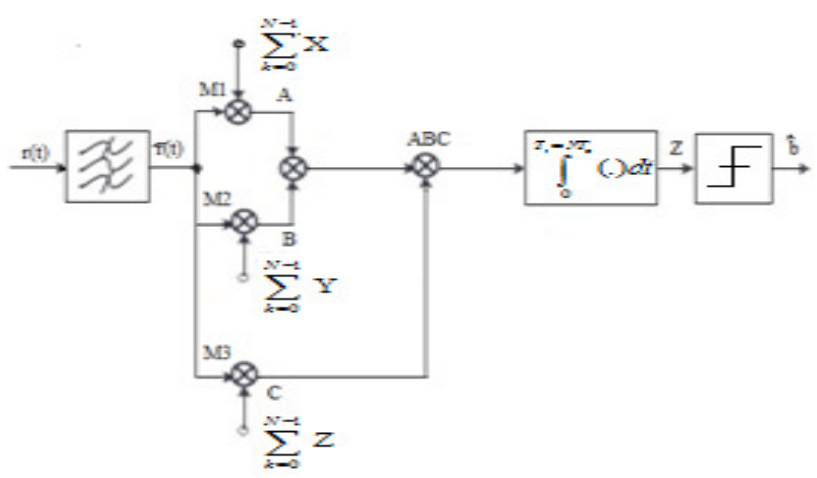

Figure.2 Block diagram of CS-QCSK Receiver

The above Figure. 2 shows the block diagram of CS-QCSK receiver. The receiver unit consists of band pass filter with the bandwidth of $2 \mathrm{~B}$ which can pass the received signal $\mathrm{r}(\mathrm{t})$ without any distortion. The receiver filter output with Additive White Gaussian Noise $(\mathrm{AWGN}) \mathrm{n}(\mathrm{t})$ is obtained as,

$$
\begin{gathered}
\tilde{r}_{r}(t)=\sum_{k=0}^{N-1} \mathrm{~W}_{\mathrm{R}, \mathrm{k}+1} \mathrm{C}_{\mathrm{x}}\left(\mathrm{t}-\mathrm{kT}_{\mathrm{c}}\right)+\mathrm{a}_{1} \sum_{k=0}^{\mathrm{N}-1} \mathrm{~W}_{\mathrm{I} 1, \mathrm{k}+1} \mathrm{C}_{\mathrm{x}}\left(\mathrm{t}-\mathrm{kT}_{\mathrm{c}}\right)+\mathrm{a}_{2} \sum_{k=0}^{\mathrm{N}-1} \mathrm{~W}_{\mathrm{I} 2, \mathrm{k}+1} \mathrm{C}_{\mathrm{y}}\left(\mathrm{t}-\mathrm{kT}_{\mathrm{c}}\right)+\mathrm{n}(\mathrm{t}) \\
\operatorname{rect}_{\mathrm{x}}\left(\mathrm{t}-\mathrm{kT}_{\mathrm{c}}\right)=\left\{\begin{array}{lc}
1 & , \mathrm{kT}_{\mathrm{c}} \leq \mathrm{t}<(k+1) \mathrm{T}_{\mathrm{c}} \\
0 & , \text { otherwise }
\end{array}\right. \\
\operatorname{rect}_{\mathrm{y}}\left(\mathrm{t}-\mathrm{kT}_{\mathrm{c}}\right)=\left\{\begin{array}{cc}
1 & , \mathrm{kT}_{\mathrm{c}} \leq \mathrm{t}<(k+1) \mathrm{T}_{\mathrm{c}} \\
0 & , \text { otherwise }
\end{array}\right.
\end{gathered}
$$

The receiver filter output is further given to the three mixer unit M1,M2 and M3.In the mixer unit the filter output signal is multiplied by a rectangular function weighted by the three Walsh code sequences. The transmitted signal is of Walsh codes incorporated with three terms. In order to obtain those terms $\mathrm{A}, \mathrm{B}$ and $\mathrm{C}$ the receiver filter output is multiplied by a rectangular function. The output of M1, M2 and M3 is multiplied to obtain the signal $\mathrm{ABC}$. The multiplier output is then given to the integrator unit to obtain the observation signal. The integrator output is given to the hard decision device, where the bits are estimated by the decision rule. Using walsh code, the transmitted signal is incorporated with three terms A, B and C. The three terms A, B and C can be obtained by multiplying equation (7) that corresponds to reference signal and information signals respectively. The terms $\mathrm{X}, \mathrm{Y}$ and $\mathrm{Z}$ in the receiver block are

$$
\mathrm{X}=\mathrm{W}_{R, \mathrm{k}+1} \operatorname{rect}_{\mathrm{x}}\left(\mathrm{t}-\mathrm{kT}_{\mathrm{c}}\right), \mathrm{Y}=\mathrm{W}_{\mathrm{I} 1, \mathrm{k}+1} \operatorname{rect}_{\mathrm{x}}\left(\mathrm{t}-\mathrm{kT}_{\mathrm{c}}\right), \mathrm{Z}=\mathrm{W}_{\mathrm{I} 2, \mathrm{k}+1} \operatorname{rect}_{y}\left(\mathrm{t}-\mathrm{kT}_{\mathrm{c}}\right) \text {. }
$$

Where,

$$
\mathrm{A}=\mathrm{S}(\mathrm{t}) \sum_{k=0}^{N-1} \mathrm{~W}_{R, \mathrm{k}+1} \text { rect }_{\mathrm{x}}\left(\mathrm{t}-\mathrm{kT}_{\mathrm{c}}\right)
$$


$\mathrm{B}=\mathrm{S}(\mathrm{t}) \sum_{k=0}^{N-1} \mathrm{~W}_{\mathrm{Il}, \mathrm{k}+1} \operatorname{rect}_{\mathrm{x}}\left(\mathrm{t}-\mathrm{kT}_{\mathrm{c}}\right)$

$C=\mathrm{S}(\mathrm{t}) \sum_{k=0}^{N-1} \mathrm{~W}_{\mathrm{I} 2, \mathrm{k}+1} \operatorname{rect}_{\mathrm{y}}\left(\mathrm{t}-\mathrm{kT}_{\mathrm{c}}\right)$

$Z=\int_{0}^{T_{s}=N T_{c}} A B C . d t$

Substituting, equation (7) in (10),(11)and(12). The equations (14), (15) and (16) are obtained.

$$
\begin{aligned}
& \mathrm{A}=\sum_{k=0}^{N-1} \mathrm{C}_{\mathrm{x}}\left(\mathrm{t}-\mathrm{kT}_{\mathrm{c}}\right)+\mathrm{a}_{1} \sum_{k=0}^{\mathrm{N}-1} \mathrm{~W}_{\mathrm{R}, \mathrm{k}+1} \mathrm{~W}_{\mathrm{I} 1, \mathrm{k}+1} \mathrm{C}_{\mathrm{x}}\left(\mathrm{t}-\mathrm{kT}_{\mathrm{c}}\right)+\mathrm{a}_{2} \sum_{k=0}^{\mathrm{N}-1} \mathrm{~W}_{\mathrm{R}, \mathrm{k}+1} \mathrm{~W}_{\mathrm{I} 2, \mathrm{k}+1} \mathrm{C}_{\mathrm{y}}\left(\mathrm{t}-\mathrm{kT}_{\mathrm{c}}\right) \\
& \mathrm{B}=\sum_{\mathrm{k}=0}^{\mathrm{N}-1} \mathrm{~W}_{\mathrm{R}, \mathrm{k}+1} \mathrm{~W}_{\mathrm{I} 1, \mathrm{k}+1} \mathrm{C}_{\mathrm{x}}\left(\mathrm{t}-\mathrm{k} \mathrm{T}_{\mathrm{c}}\right)+\mathrm{a}_{1} \sum_{\mathrm{k}=0}^{N-1} \mathrm{C}_{\mathrm{x}}\left(\mathrm{t}-\mathrm{kT}_{\mathrm{c}}\right) \\
& \mathrm{C}=\sum_{\mathrm{k}=0}^{\mathrm{N}-1} \mathrm{~W}_{\mathrm{R}, \mathrm{k}+1} \mathrm{~W}_{\mathrm{I} 2, \mathrm{k}+1} \mathrm{C}_{\mathrm{x}}\left(\mathrm{t}-\mathrm{k} \mathrm{T}_{\mathrm{c}}\right)+\mathrm{a}_{2} \sum_{\mathrm{k}=0}^{N-1} \mathrm{C}_{\mathrm{y}}\left(\mathrm{t}-\mathrm{kT}_{\mathrm{c}}\right)
\end{aligned}
$$

Substituting equation (14), (15) and (16) in (13)

$$
\begin{aligned}
& Z=\int_{0}^{T_{s}=N T_{\mathrm{c}}}\left(\sum_{\mathrm{k}=0}^{N-1} \mathrm{C}_{\mathrm{x}}\left(\mathrm{t}-\mathrm{kT} \mathrm{T}_{\mathrm{c}}\right)+\mathrm{a}_{1} \sum_{\mathrm{k}=0}^{\mathrm{N}-1} \mathrm{~W}_{\mathrm{R}, \mathrm{k}+1} \mathrm{~W}_{\mathrm{Il}, \mathrm{k}+1} \mathrm{C}_{\mathrm{x}}\left(\mathrm{t}-\mathrm{kT}_{\mathrm{c}}\right)+\mathrm{a}_{2} \sum_{\mathrm{k}=0}^{\mathrm{N}-1} \mathrm{~W}_{\mathrm{R}, \mathrm{k}+1} \mathrm{~W}_{\mathrm{I} 2, \mathrm{k}+1} \mathrm{C}_{\mathrm{y}}\left(\mathrm{t}-\mathrm{kT}_{\mathrm{c}}\right)\right) . \\
& \left(\sum_{\mathrm{k}=0}^{\mathrm{N}-1} \mathrm{~W}_{\mathrm{R}, \mathrm{k}+1} \mathrm{~W}_{\mathrm{I}, \mathrm{k}+1} \mathrm{C}_{\mathrm{x}}\left(\mathrm{t}-\mathrm{kT} \mathrm{c}_{\mathrm{c}}\right)+\mathrm{a}_{1} \sum_{\mathrm{k}=0}^{N-1} \mathrm{C}_{\mathrm{x}}\left(\mathrm{t}-\mathrm{kT} \mathrm{T}_{\mathrm{c}}\right)\right)\left(\sum_{\mathrm{k}=0}^{\mathrm{N}-1} \mathrm{~W}_{\mathrm{R}, \mathrm{k}+1} \mathrm{~W}_{\mathrm{I} 2, \mathrm{k}+1} \mathrm{C}_{\mathrm{x}}\left(\mathrm{t}-\mathrm{kT}_{\mathrm{c}}\right)+\mathrm{a}_{2} \sum_{\mathrm{k}=0}^{N-1} \mathrm{C}_{\mathrm{y}}\left(\mathrm{t}-\mathrm{kT}_{\mathrm{c}}\right)\right) d t
\end{aligned}
$$

The above equation (17) can be simplified as,

$$
Z \cong a_{1} a_{2} E_{b}
$$

\section{Analytical Derivation of BER Under VARYing ChanNels}

The analytical expression for the BER of CS-QCSK over AWGN and the multipath Rayleigh fading channels are derived in the following section.

\subsection{Additive White Gaussian Noise (AWGN) Channel}

From the receiver unit, the observation variable obtained is given by

$$
\begin{aligned}
& \mathrm{Z}=\sum_{k=0}^{N-1} \int_{\mathrm{kT}}^{(\mathrm{k}+1) \mathrm{T}_{\mathrm{c}}}\left[\mathrm{W}_{\mathrm{R}, \mathrm{k}+1} \cdot{ }_{r}(t)\right]\left[\mathrm{W}_{\mathrm{I} 1, \mathrm{k}+1} \mathrm{~W}_{\mathrm{I} 2, \mathrm{k}+1} \cdot{ }_{r}(t)\right] \mathrm{dt} \\
& =\sum_{\mathrm{k}=0}^{\mathrm{N}-1} \mathrm{~W}_{\mathrm{R}, \mathrm{k}+1} \mathrm{~W}_{\mathrm{I} 1, \mathrm{k}+1} \mathrm{~W}_{\mathrm{I} 2, \mathrm{k}+1} \int_{\mathrm{kT}}^{(\mathrm{k}+1) \mathrm{T}_{\mathrm{c}}}\left[\left(\mathrm{W}_{\mathrm{R}, \mathrm{k}+1}+\mathrm{a}_{1} \mathrm{~W}_{\mathrm{I} 1 \mathrm{k}+1}+\mathrm{a}_{2} \mathrm{~W}_{\mathrm{I} 2, \mathrm{k}+1}\right)+c\left(t-k T_{c}\right)+n(t)\right]^{2} \cdot d t
\end{aligned}
$$


There are different types of chaotic maps to generate the chaotic signals, they are classified as (i)logistic map (ii) cubic map (iii) Bernoulli-shift map. In the proposed method, logistic map is considered and is defined as, $x(n+1)=1-2 x^{2}(n)$. Where, $\beta=T_{c} f_{s}$ is the number of samples in a chip time and $\mathrm{K}=\mathrm{T}_{\mathrm{s}} \mathrm{f}_{\mathrm{s}}=\mathrm{N} \beta$ is the symbol duration. In the remaining part of the paper, ' $\mathrm{K}$ ' is referred as the spreading factor. Consider, the transmission of $\mathrm{a} 1=\mathrm{a} 2=+1$ sequence. The logistic map is defined in the continuous time domain. In order to convert into the discrete time domain, consider $C_{j}$ be the samples of chaotic signal and $\eta_{j}$ be the channel noise. Then, the equation for discrete time equivalent is given as,

$$
Z=\sum_{\mathrm{k}=0}^{\mathrm{N}-1} \mathrm{~W}_{\mathrm{R}, \mathrm{k}+1} \mathrm{~W}_{\mathrm{I} 1, \mathrm{k}+1} \mathrm{~W}_{\mathrm{I} 2, \mathrm{k}+1} \sum_{\mathrm{m}=1}^{\beta}\left[\left(\mathrm{W}_{\mathrm{R}, \mathrm{k}+1}+\mathrm{a}_{1} \mathrm{~W}_{\mathrm{I} 1, \mathrm{k}+1}+\mathrm{a}_{2} \mathrm{~W}_{\mathrm{I} 2, \mathrm{k}+1}\right) \cdot c_{k \beta+m}+\eta_{k \beta+m}\right]^{2}
$$

Where,

$$
c_{k \beta+m}=\left\{\begin{array}{lr}
c_{m} & , \kappa \beta \leq \kappa \beta+m<(k+1) \beta \\
0 & \text {, otherwise }
\end{array}\right.
$$

From the equation (21), the decision variable is decomposed into three terms,

$$
Z=Z_{A}+Z_{B}+Z_{C}
$$

where,

$$
\begin{aligned}
& Z_{A}=\sum_{\mathrm{k}=0}^{\mathrm{N}-1} \mathrm{~W}_{\mathrm{R}, \mathrm{k}+1} \mathrm{~W}_{\mathrm{I} 1, \mathrm{k}+1} \mathrm{~W}_{\mathrm{I} 2, \mathrm{k}+1} \sum_{\mathrm{m}=1}^{\beta}\left[\left(\mathrm{W}_{\mathrm{R}, \mathrm{k}+1}+\mathrm{a}_{1} \mathrm{~W}_{\mathrm{I} 1, \mathrm{k}+1}+\mathrm{a}_{2} \mathrm{~W}_{\mathrm{I} 2, \mathrm{k}+1}\right)^{2}\left(c_{k \beta+m}\right)^{2}\right] \\
& Z_{B}=\sum_{\mathrm{k}=0}^{\mathrm{N}-1} \mathrm{~W}_{\mathrm{R}, \mathrm{k}+1} \mathrm{~W}_{\mathrm{I} 1 \mathrm{k}+1} \mathrm{~W}_{\mathrm{I} 2, \mathrm{k}+1} \sum_{\mathrm{m}=1}^{\beta}\left[\left(\mathrm{W}_{\mathrm{R}, \mathrm{k}+1}+\mathrm{a}_{1} \mathrm{~W}_{\mathrm{I} 1, \mathrm{k}+1}+\mathrm{a}_{2} \mathrm{~W}_{\mathrm{I} 2, \mathrm{k}+1}\right)\left(c_{k \beta+m}\right)\left(\eta_{k \beta+m}\right)\right] \\
& Z_{C}=\sum_{\mathrm{k}=0}^{\mathrm{N}-1} \mathrm{~W}_{\mathrm{R}, \mathrm{k}+1} \mathrm{~W}_{\mathrm{I} 1, \mathrm{k}+1} \mathrm{~W}_{\mathrm{I} 2, \mathrm{k}+1} \sum_{\mathrm{m}=1}^{\beta}\left(c_{k \beta+m}\right)^{2}
\end{aligned}
$$

By applying, Expectation and Variance to the above equations, (24), (25) and (26) the expectation and variance values of these variables are obtained as,

$$
\begin{aligned}
& E\left\{Z_{A} \mid b=1\right\}=E\left\{Z_{A} \mid a=+1\right\}=3 N \beta E\left\{C_{j}^{2}\right\} \\
& E\left\{Z_{B} \mid b=1\right\}=E\left\{Z_{B} \mid a=+1\right\}=0 \\
& E\left\{Z_{C} \mid b=1\right\}=E\left\{Z_{C} \mid a=+1\right\}=0 \\
& \operatorname{Var}\left\{Z_{A} \mid b=1\right\}=\operatorname{Var}\left\{Z_{A} \mid a=+1\right\}=3 N \beta \operatorname{Var}\left\{C_{j}^{2}\right\} \\
& \operatorname{Var}\left\{Z_{B} \mid b=1\right\}=\operatorname{Var}\left\{Z_{B} \mid a=+1\right\}=2 N \beta N_{0} \operatorname{Var}\left\{C_{j}^{2}\right\} \\
& \operatorname{Var}\left\{Z_{C} \mid b=1\right\}=\operatorname{Var}\left\{Z_{C} \mid a=+1\right\}=N \beta N_{0}^{2}
\end{aligned}
$$

Where, $\mathrm{E}\{$.$\} represents the expectation operator and \operatorname{var}\{$.$\} represents the variance operator ,then$

$$
E\{Z \mid b=1\}=E\{Z \mid a=+1\}=3 N \beta E\left\{C_{j}^{2}\right\}
$$


$\operatorname{Var}\{Z \mid b=1\}=\operatorname{Var}\{Z \mid a=+1\}=3 N \beta \operatorname{Var}\left\{C_{j}^{2}\right\}+2 N \beta N_{0} \operatorname{Var}\left\{C_{j}^{2}\right\}+N \beta N_{0}^{2}$

For the transmission of ' $\mathrm{a}_{1}=\mathrm{a}_{2}=-1$ ' sequence, the expectation and variance of observation variable is derived similarly.

$$
\begin{aligned}
& E\{Z \mid a=-1\}=-E\{Z \mid a=+1\} \\
& \operatorname{Var}\{Z \mid a=-1\}=\operatorname{Var}\{Z \mid a=+1\}
\end{aligned}
$$

It is assumed, that the probability distribution of the observation variable can be approximated by gaussian approximation and the transmitted bits are equiprobable. Therefore, the bit error rate of CS-QCSK modulation scheme is obtained as,

$$
\begin{aligned}
& B E R=\frac{1}{2} \operatorname{Pr}\left(Z_{m}<0 \mid b=1\right)+\frac{1}{2} \operatorname{Pr}\left(Z_{m} \geq 0 \mid b=0\right) \\
& =\frac{1}{2} \operatorname{Pr}\left(Z_{m}<0 \mid a=+1\right)+\frac{1}{2} \operatorname{Pr}\left(Z_{m} \geq 0 \mid a=-1\right) \\
& =\frac{1}{2} \operatorname{erfc}\left(\frac{E\left\{Z_{m} \mid a=+1\right\}}{\sqrt{2 \operatorname{Var}\left\{Z_{m} \mid a=+1\right\}}}\right)
\end{aligned}
$$

Where, $m=2$; represents the number of information bits transmitted per time slot.For logistic maps, the expectation of chaos signal is $E\left\{C_{j}^{2}\right\}=1 / 2$ and variance of chaos signal is $\operatorname{Var}\left\{C_{j}^{2}\right\}=1 / 8$ and therefore equation (37) becomes,

$$
\begin{aligned}
& =\frac{1}{2} \operatorname{erfc}\left(\frac{3 N \beta E\left\{C_{j}^{2}\right\}}{\sqrt{2\left(3 N \beta \operatorname{Var}\left\{C_{j}^{2}\right\}+2 N \beta N_{0} \operatorname{Var}\left\{C_{j}^{2}\right\}+N \beta N_{0}^{2}\right)}}\right) \\
& B E R_{C S-Q C S K}=\frac{1}{2} \operatorname{erfc}\left(\frac{3\left(E_{b} / N_{0}\right)}{\sqrt{\frac{3}{4} K+\frac{1}{2} K+2\left(E_{b} / N_{0}\right)}}\right)
\end{aligned}
$$

\subsection{Rayleigh Multipath Fading Channel}

Considering the rayleigh multipath fading channels, the received signal is denoted as

$$
r(t)=h(t) \otimes x(t)+n(t)
$$

and the channel impulse response is given as

$$
h(t)=\sum_{l=0}^{L-1} \alpha_{l} \delta(l-\eta)
$$

Where, $\mathrm{L}$ is the number of propagation paths, $\alpha_{1}$ gain of the lth path, $\tau \mathrm{l}$ is the delay of the $1^{\text {th }}$ path and $\delta(t)$ denotes the dirac delta function. The gains $\alpha_{1}$ of the propagation paths are assumed to be independent identical distributed Rayleigh random variables. The BER measured in Rayleigh multipath channel is an approximation developed from the noise performance of AWGN channel. The conditional BER measured for the multipath is given by, 
$\operatorname{BER}\left(\alpha_{0}, \alpha_{1 \ldots \ldots \ldots . . .} \alpha_{\mathrm{L}-1}\right)=\operatorname{BER}\left(\gamma_{\mathrm{b}}\right)$

Where, $\gamma_{\mathrm{b}}=\left(\mathrm{E}_{\mathrm{b}} / \mathrm{N}_{\mathrm{o}}\right)\left(\alpha_{0}, \alpha_{1} \ldots \ldots \ldots \alpha_{\mathrm{L}-1}\right)=\left(\gamma_{0}+\gamma_{1}+\ldots \ldots \ldots \ldots \ldots+\gamma_{\mathrm{L}-1}\right)$

The probability density function (PDF)of $\gamma_{\mathrm{i}}$ is an exponential distribution given by,

$$
f(x)=\frac{1}{\gamma_{k}} \exp \left(\frac{-x}{\gamma_{k}}\right)
$$

The probability density function (pdf) of $\gamma_{\mathrm{b}}$ is obtained as,

$$
f\left(\gamma_{\mathrm{b}}\right)=f\left(\gamma_{0}\right) \otimes f\left(\gamma_{1}\right) \ldots \ldots \ldots \ldots \otimes f\left(\gamma_{L-1}\right)
$$

Where, $f\left(\gamma_{k}\right)$ is the pdf of instantaneous (SNR) measured in the ith path. By averaging the conditional bit error rates in the multipath channels, the total BER measured is obtained as,

$$
B E R=\int_{0}^{\infty} B E R\left(\gamma_{\mathrm{b}}\right) f\left(\gamma_{\mathrm{b}}\right) d \gamma_{\mathrm{b}}
$$

In this paper, it is assumed to have two multipath channels with three propagation paths, then the error rate expressions are

$$
B E R_{C S-Q C S K}=\frac{1}{2} \operatorname{erfc}\left(\frac{3\left(\gamma_{b}\right)}{\sqrt{\frac{3}{4} K+\frac{1}{2} K+2\left(\gamma_{b}\right)}}\right)
$$

In order to validate the analytical approach of the proposed scheme, an attempt is made through simulations. The next section presents the simulation analysis of the proposed scheme and it is finally compared with the analytical results.

\section{Simulation ANAlysis}

The BER performances of CS-QCSK modulation schemes for different channel conditions are also analyzed through Matlab simulation. Simulation parameters taken for the analysis are chip duration $(\mathrm{Tc})=2$ millisecond,Symbol duration $(\mathrm{Ts})=2$ micro second, transmission power $(\mathrm{P})=43 \mathrm{dBm}$, noise power spectral density $(\mathrm{No})=1$, spread factor $(\mathrm{K})=40$, the channel types are AWGN and Rayleigh . Firstly, the BER performance of AWGN channel is discussed, followed by multipath Rayleigh fading channel.

\subsection{BER Performance over AWGN Channel}

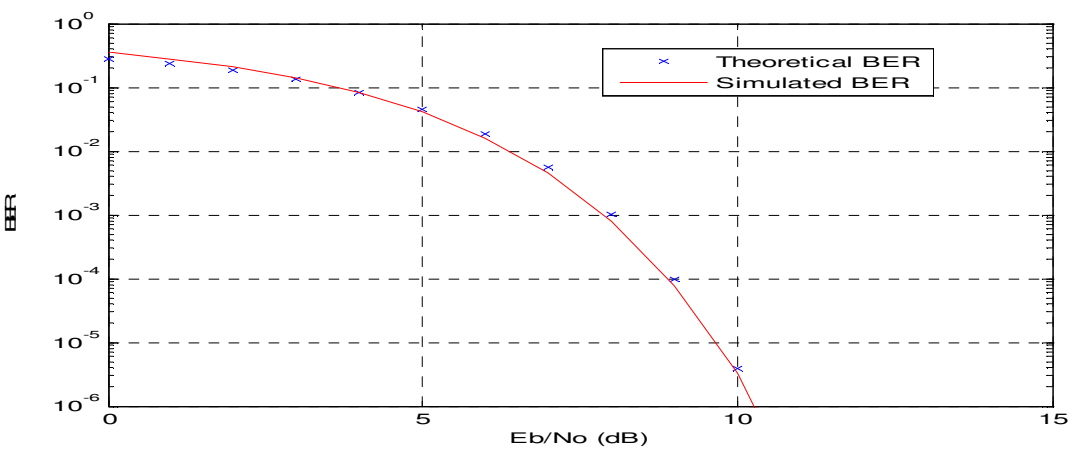

Figure. 3 BER performance of CS-QCSK modulation scheme for AWGN channel. 
From the figure.3, it is inferred that BER performance of CS-QCSK scheme is plotted with the theoretical and simulated values.The BER values calculated from the analytical expression and the simulation are very similar and both the graph merge with each other.For the BER value of $10^{-6}$, the required (Eb/No) value is $10 \mathrm{~dB}$ (approximately).

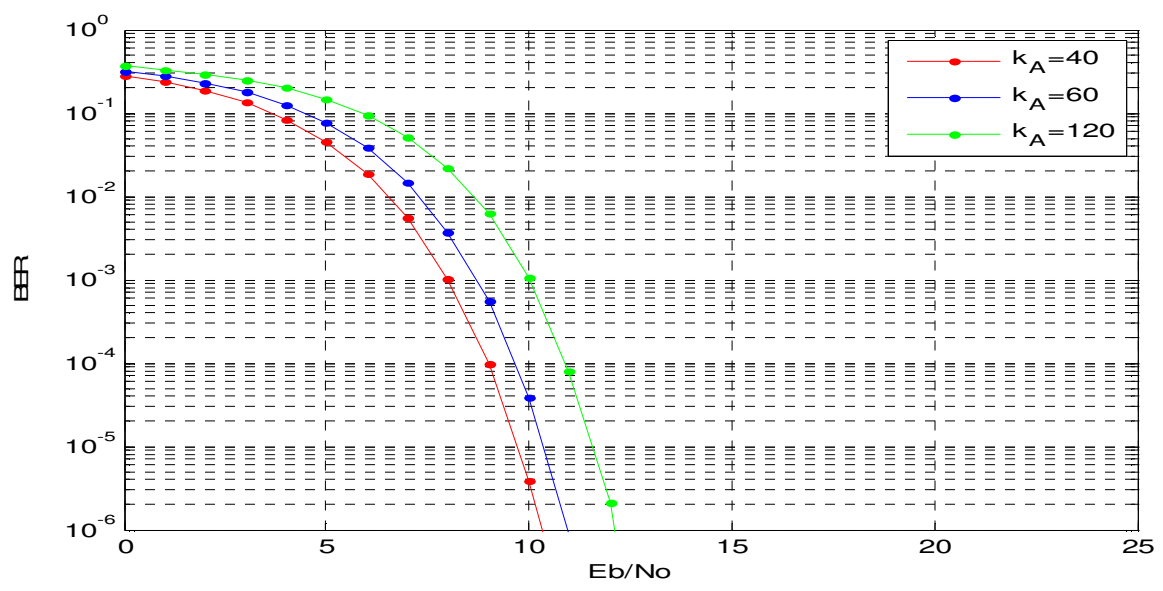

Figure.4 BER performance of the CS-QCSK modulation scheme over AWGN channel for various spread factor.

BER performance of CS-QCSK modulation scheme for various spreading factors $(\mathrm{K}=40$, $\mathrm{K}=80, \mathrm{~K}=120$ ) were plotted. It is inferred from the above graph that, as the $\mathrm{K}$ value increases the noise performance become worse. In general, smaller Spreading factor corresponds to minimum noise level. Therefore, for smaller values of ' $K$ ' the BER performance is better.

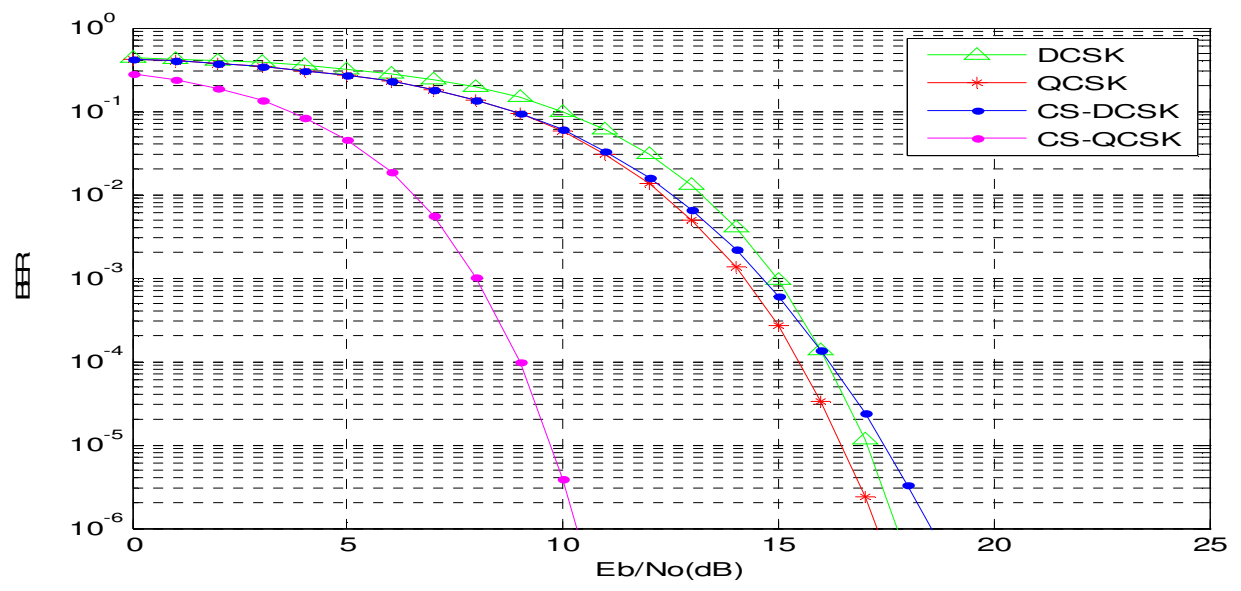

Figure. 5 BER performance comparison for different modulation schemes with CSQCSK modulation scheme Over AWGN channel.

In the above graph, the BER performance of different modulation schemes were compared. For the BER value of 10-1, the required Eb/No value for CS-DCSK, DCSK, QCSK and CS-QCSK is $18.4 \mathrm{~dB}, 17.8 \mathrm{~dB}, 17.2 \mathrm{~dB}$ and $10.2 \mathrm{~dB}$ respectively. On inferring these Eb/No values, the BER performance of proposed CS-QCSK modulation scheme is better compared to the DCSK, CSDCSK and QCSK modulation schemes. 


\subsection{BER Performance over Rayleigh Multipath Channel}

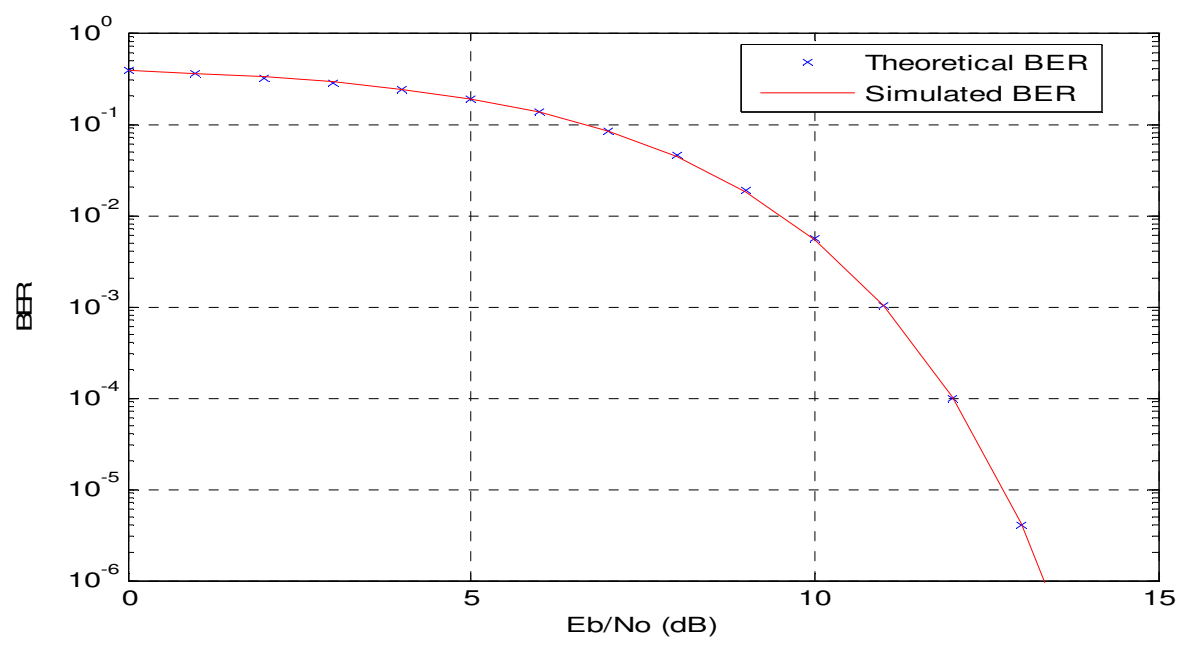

Figure. 6 BER performance of CS-QCSK modulation scheme for Rayleigh multipath channel.

From the above figure, it is inferred that BER performance of CS-QCSK scheme is plotted with the theoretical and simulated values.The BER values calculated from the analytical expression and the simulation are very similar and both the graph merge with each other.For the BER value of $10^{-6}$, the required (Eb/No) value is $13.1 \mathrm{~dB}$ (approximately).

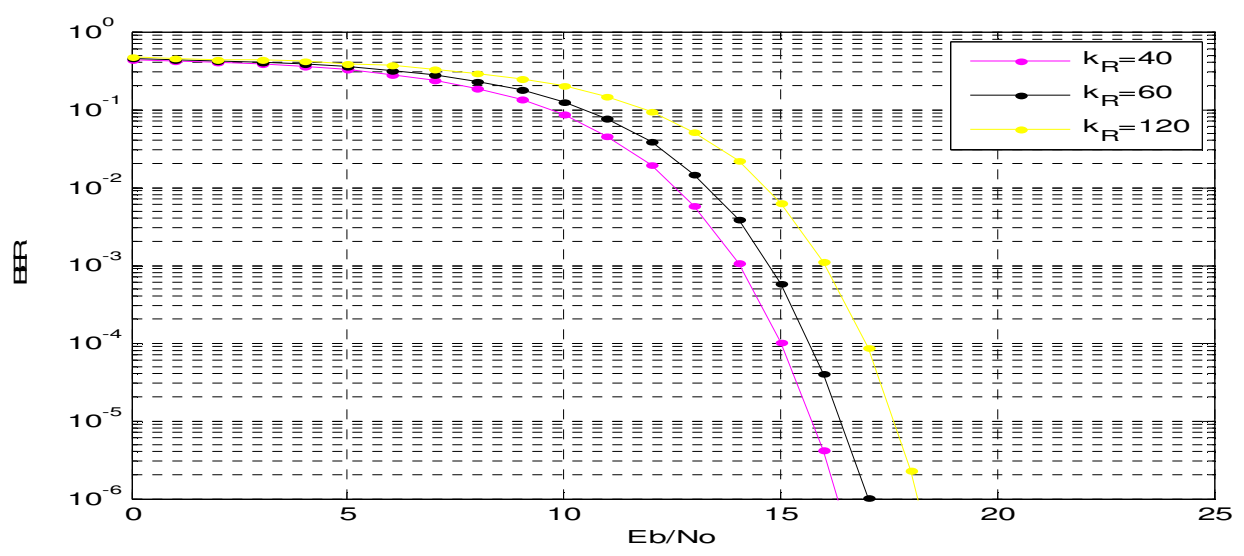

Figure.7 BER performance of the CS-QCSK modulation scheme over Rayleigh channel for various spread factor.

BER performance of CS-QCSK modulation scheme for various spreading factors $(K=40$, $\mathrm{K}=80, \mathrm{~K}=120$ ) were plotted. It is inferred from the above graph that, as the $\mathrm{K}$ value increases the noise performance become worse. In general, smaller Spreading factor corresponds to minimum noise level. Therefore, for smaller values of ' $\mathrm{K}$ ' the BER performance is better. 


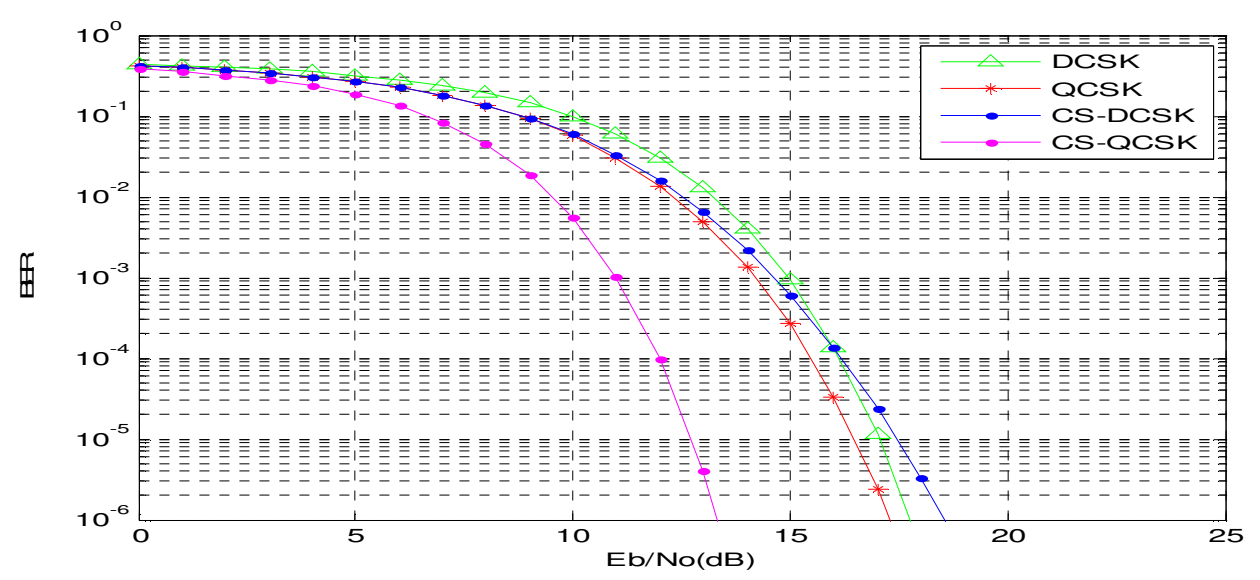

Figure. 8 BER performance comparison for different modulation schemes with CSQCSK modulation scheme Over AWGN channel.

In the above graph, the BER performance of different modulation schemes were compared. For the BER value of 10-1, the required Eb/No value for CS-DCSK,DCSK,QCSK and CS-QCSK is $18.8 \mathrm{~dB}, 18 \mathrm{~dB}, 17.4 \mathrm{~dB}$ and $13.1 \mathrm{~dB}$ respectively. On inferring these Eb/No values, the BER performance of proposed CS-QCSK modulation scheme is better compared to the DCSK, CSDCSK and QCSK modulation schemes.

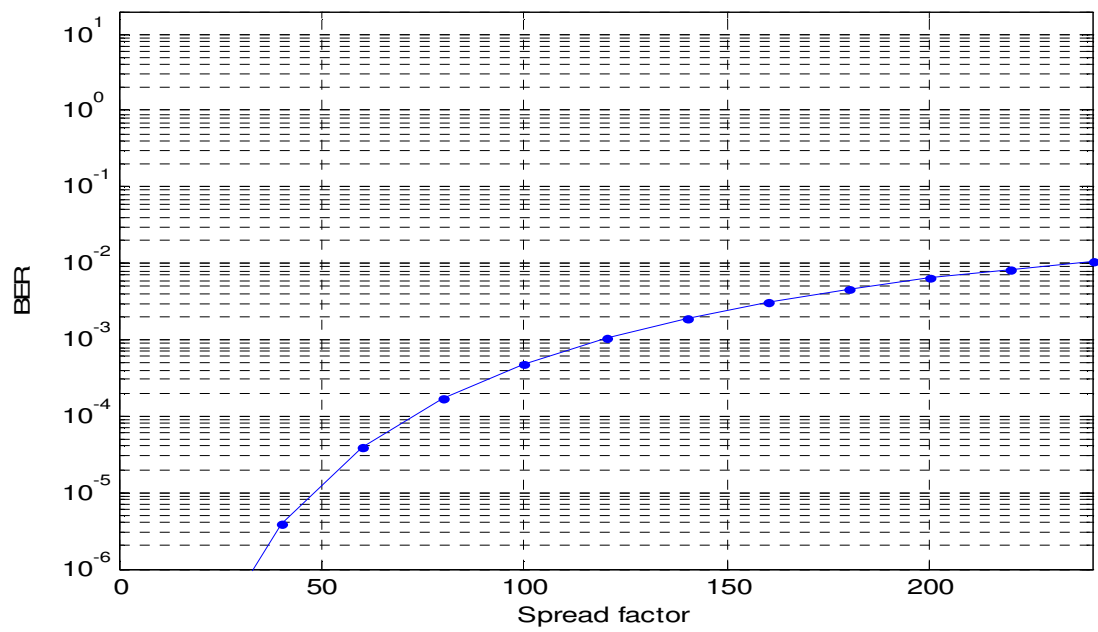

Figure. 9 Effect of spreading factor on BER performance of the CS-QCSK modulation scheme. Eb/No has been fixed at $10 \mathrm{~dB}$.

BER is plotted against the spreading factor by fixing $\mathrm{Eb} / \mathrm{No}$ at $10 \mathrm{~dB}$.It is inferred that, larger the spreading factor, worse the performance.

\section{Conclusion}

In the field of chaos-based communication, M-ary DCSK scheme seems to be the best known modulation scheme. But, the drawback is, it requires $(\mathrm{N}-1)$ number of of delay lines both in the transmitter and the receiver units. In this paper, an improved chaos-based communication method 
using CS-QCSK technique is recommended. The proposed CS-QCSK scheme, avoids the use of delay lines in the receiver units. It transmits the reference and information signals in the same time slot and offers an increase in data rate, better BER performance and bandwidth efficiency. The performance of the proposed modulation scheme is analyzed in context of AWGN and multipath channels. Analytical expressions for BER of CS-QCSK are derived and verified with matlab simulation. Simulation results, shows that the CS-QCSK has better BER performance in AWGN and Rayleigh fading channels, when compared with the conventional modulation schemes. This proves the suitability of the proposed modulation technique for a mobile radio scenario, which is the need of the hour.

\section{REFERENCES}

[1] Abel and W. Schwarz, "Chaos communications-Principles, schemes, and system analysis," Proc. IEEE, vol. 90,pp. 691-710, May 2002

[2] G. Kolumbán, M. P. Kennedy, Z. Jako, and G. Kis, "Chaotic communications with correlator receivers: Theory andperformance limits,” Proc.IEEE, vol. 90, pp. 711-732, May 2002.

[3] H. Dedieu, M. P. Kennedy, and M. Hasler,"Chaos shift keying: Modulation and demodulation of a chaotic carrier using self-synchronizing Chua's circuits,” IEEE Trans. Circuits Syst. II, vol. 40, pp. 634-642, Oct.1993.

[4] G. Kolumbán, B. Vizvári,W. Schwarz, and A. Abel, "Differential chaos shift keying: A robust coding for chaos communication,” Proc. Int.Workshop Nonlinear Dynamics of Electronic Systems, pp. 8792, June 1996.

[5] G. Kolumbán, G. Kis, M. P. Kennedy, and Z. Jáko, "FM-DCSK: A new and robust solution to chaos communications," in Proc., Int. Symp. Nonlinear Theory Appl., HI, 1997, pp. 117- 120.

[6] M. P. Kennedy and G. Kolumbán, "Digital communication using chaos,"in Controlling Chaos and Bifurcation in Engineering Systems, G. Chen, Ed. Boca Raton, FL: CRC, 2000, pp. 477- 500.

[7] G. Kolumbán and M. P. Kennedy, "The role of synchronization in digital communications using chaos-Part III:Performance bounds for correlation receivers," IEEE Trans. CircuitsSyst. I, Fundamental. Theory Appl.,vol. 47, no. 12, pp. 1673-1683, Dec. 2000.

[8] G.Kolumban, Z. Jákó, and M. P.Kennedy, "Enhanced versions of DCSK and FM-DCSK data transmissions systems,” in Proc. IEEE ISCAS'99, vol. IV, Orlando, FL, May/Jun. 1999, pp. 475-478.

[9] M. P. Kennedy, G. Kolumbán, G. Kis, and Z. Jákó, "Performance evaluation of FM-DCSK modulation in multipath environments," IEEE Trans.Circuits Syst. I, Fundam. Theory Appl., vol. 47, no. 12 , pp. 1702-1711, Dec.2000.

[10] G. Kolumbán, "Theoretical noise performance of correlator-based chaotic communications schemes," IEEE Trans. Circuits Syst. I, Fundam. Theory Appl., vol. 47, no. 12, pp. 1692- 1701, Dec. 2000.

[11] Z. Galias and G. M. Maggio, "Quadrature chaos-shift keying: Theory and performance analysis," IEEE Trans.Circuits Syst. I, Fundam.Theory Appl., vol. 48, no. 12, pp. 1510-1519, Dec. 2001.

[12] G. Kolumbán and G. Kis, "Multipath performance of FM-DCSK chaotic communications system," in Proc. IEEE Int. Symp. Circuits and Systems, Geneva, Switzerland, May 2000, pp. 433-436.

[13] S. Mandal and S. Banerjee, "Performance of differential chaos shift keying over multipath fading channels," in Proc. Indian Nat. Conf. Nonlinear Systems and Dynamics, Kharagpur, India, Dec. 2003.

[14] G. Kolumbán, P. Kennedy, and G. Kis, "Multilevel differential chaos shift keying," in Proc. Int. Workshop, Nonlinear Dynamics of Electronics Systems, NDES'97, Moscow, Russia, 1997, pp. 191196.

[15] F. C. M. Lau, M. M. Yip, C. K. Tse, and S. F. Hau, “A Multiple-Access Technique for Differential Chaos-Shift Keying” IEEE Trans.Circuits Syst. I, Fundam.Theory Appl., vol. 49, no. 1, January 2002.

[16] YiWei Zhang, Xubang Shen and Yi Ding, "Design and performance analysis of an FM- QCSK chaotic communication system," International Conference on Wireless Communications, Networking and Mobile Computing, China, pp: 1-4, Sept. 2006.

[17] Jiamin Pan, He Zhang, "Design of FM-QACSK Chaotic Communication System" IEEE trans. Wireless Communications \& Signal Processing, 2009.

[18] Xia, Y.,Tse,C.K.\& Lau, F.C.M, "Performance of differential chaos shift keying digital communication systems over a multipath fading channel with delay spread,'IEEE Trans. Circuits Syst.-II 51,680-684,2004.

[19] Yao,J.\& Lawrance, A.J, “ Performance analysis and optimization of multi-user differential chaosshift keying communication systems,” IEEE Trans.circ. Syst.-I 53, pp.2075-2091, 2006. 
[20] Wang,L.,Zhang,C.\& Chen, G. "Performance of an SIMO FM-DCSK communication system," IEEE Trans.Circuits Syst.-II, 55, 457-461,2008.

[21] Min,X.,Xu,W.,Wang, L. \& Chen, G., "Promising performance of an FM-DCSK UWB system under indoor environments," J. IET Commun. 4, pp.125-134, 2010.

[22] G.Koluban,W.K.Xu and L.Wang, "A Novel differential chaos shift keying modulation scheme," International journal of Bifurcation and chaos,2011,Vol.21,No.3,pp799-814

\section{Authors}

K.Jayanthi received B.E degree from University of Madras in 1997 and M.Tech degree in Electronics and Communication Engineering and Ph.D from Pondicherry University in 1999 and 2007 respectively. She has 13years of experience in teaching / research. She is currently serving as Associate Professor in Department of Electronics and Communication Engineering, Pondicherry Engineering College, Puducherry. To her credit, she has around 12 journal papers and presented 18 papers in International conferences. Her other areas of interest includes satellite communication, Wireless multimedia networks, Spread spectrum communication, Image processing, etc. She has authored a book on Qos Provisioning in Cellular Mobile Networks.

K.Thilagam received her B.Tech and M.Tech degrees in Electronics and Communication Engineering from Pondicherry Engineering College in 2004 and 2007 respectively. She has 5 years of experience in teaching/research. She is currently pursuing Ph.D in the area of Wireless Communication. Her research activities are focussed on Cooperative Communication in Cellular Networks, mainly on Modulation and coding techniques, etc
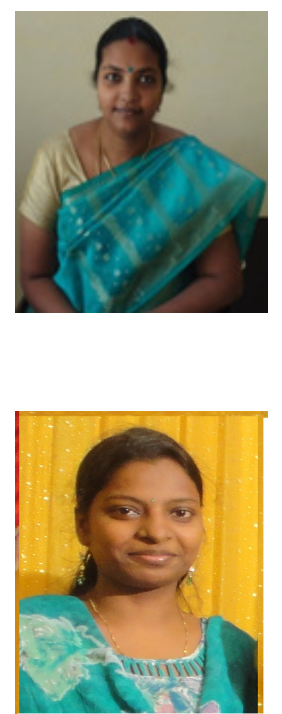